\title{
КОГНИТИВНЫЕ КАРТЫ КОМПЕТЕНЦИЙ РАЗВИТИЯ ЧЕЛОВЕЧЕСКОГО КАПИТАЛА В ВЫСОКОТЕХНОЛОГИЧНЫХ И НАУКОЕМКИХ ОТРАСЛЯХ ЭКОНОМИКИ
}

\section{COGNITIVE MAPS OF COMPETENCIES FOR THE DEVELOPMENT OF HUMAN CAPITAL IN HIGH-TECH AND KNOWLEDGE-INTENSIVE SECTORS OF THE ECONOMY}

\section{Melnichuk}

Summary. A cognitive map of human capital development competencies in high-tech and knowledge-intensive sectors of the economy is proposed, which is a formalized relationship between variables and allows one to assess the predictors that most strongly influence each other.

In order to build a cognitive map, a survey of experts was conducted, which made it possible to establish the most stable relationship between the studied competencies. Determination of the relationship between competencies was based on the assessment of their intensity, determined according to the scale developed by the author for assessing the degree of mutual influence of the analyzed variables. A matrix of mutual influence of the studied variables has been developed and the degree of their interaction has been determined.

Keywords: human capital; cognitive map; competence; cognitive modeling.
$\mathbf{M}$ оделирование сложных систем, получившее широкое распространение с применением ресурсов Big Data, возможно для множеств, в которых взаимосвязи между показателями количественно определяемы. Для неявных количественных связей между анализируемыми переменными применяется методология когнитивного моделирования, родоначальником которой является Р. Аксельрод $[1,2]$ (сам термин «когнитивные карты» впервые был использован в работе ученого-психолога Толмена).

Когнитивное моделирование может базироваться на оценке переменных любым известным методом экспертных оценок, (анкетирование, интервью, метод Дельфи, мозговой штурм и др.), которые позволяют объективно с профессиональной точки зрения определить взаимосвязи в преломлении к их качественным

\author{
Мельничук Марина Владимировна \\ Д.э.н., профессор, Финансовый университет при \\ ПравительствеРФ \\ MVMelnichuk@fa.ru
}

Аннотация. Предложена когнитивная карта компетенций развития человеческого капитала в высокотехнологичных и наукоемких отраслях экономики, представляющая собой формализованные взаимосвязи между переменными и позволяющая оценить предикторы, наиболее сильно влияющие друг на друга.

В целях построения когнитивной карты было проведено анкетирование экспертов, которое позволило установить наиболее устойчивые взаимосвязи межу исследуемыми компетенциями. Определение взаимосвязей между компетенциями основывалось на оценке их интенсивности, определяемой согласно разработанной автором шкале оценивания степени взаимного влияния анализируемых переменных. Разработана матрица взаимного влияния исследуемых переменных и определена степень их взаимодействия.

Ключевые слова: человеческий капитал; когнитивная карта; компетенции; когнитивное моделирование.

характеристикам; на моделях статистического анализа, методах сценарного анализа, SWOT-анализа, PEST- анализа и др. [3-6].

Базовым инструментом когнитивного моделирования выступает когнитивная карта, демонстрирующая качественные взаимосвязи между анализируемыми предикторами. Формализация модели в форме когнитивной карты позволяет определить направление воздействия на выбранный набор переменных (в рамках анализируемых показателей) в целях достижения заданного результата [7-9].

Следует пояснить, что построение когнитивной карты основано на казуальных представлениях о взаимодействии переменных и может использоваться для конкретной, вошедшей в выборку аудитории [10-14]. 
Таблица 1. Шкала оценивания степени взаимного влияния анализируемых переменных

\begin{tabular}{|c|c|c|c|}
\hline $\begin{array}{l}\text { Степень влияния } \\
\text { фактора (переменной) }\end{array}$ & Характеристика & $\begin{array}{l}\text { Степень влияния фактора } \\
\text { (переменной }\end{array}$ & Характеристика \\
\hline$(+0,1)-(+1)$ & $\begin{array}{l}\text { Очень слабое положительное } \\
\text { влияние }\end{array}$ & $0-(-1)$ & $\begin{array}{l}\text { Очень слабое отрицательное } \\
\text { влияние }\end{array}$ \\
\hline$(+1,1)-(+2)$ & Слабое положительное влияние & $(-1,1)-(-2)$ & Слабое отрицательное влияние \\
\hline$(+2,1)-(+3)$ & Умеренное положительное влияние & $(-2,1)-(-3)$ & Умеренное отрицательное влияние \\
\hline$(+3,1)-(+4)$ & Сильное положительное влияние & $(-3,1)-(-4)$ & Сильное отрицательное влияние \\
\hline$(+4,1)-(+5)$ & $\begin{array}{l}\text { Очень сильное положительное } \\
\text { влияние }\end{array}$ & $(-4,1)-(-5)$ & $\begin{array}{l}\text { Очень сильное отрицательное } \\
\text { влияние }\end{array}$ \\
\hline
\end{tabular}

Источник: разработано автором

Таблица 2. Матрица взаимного влияния компетенций (разработано автором)

\begin{tabular}{|c|c|c|c|c|c|c|c|c|c|c|c|c|}
\hline & & K1 & K2 & K3 & K4 & K5 & K6 & K7 & K8 & K9 & K10 & \\
\hline $\begin{array}{l}\text { Исс } \\
\text { вза }\end{array}$ & $\begin{array}{l}\text { едуемые переменные/ } \\
\text { мное влияние }\end{array}$ & 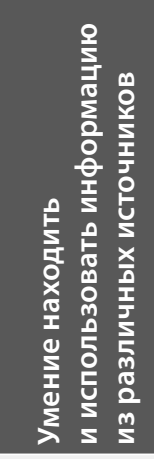 & 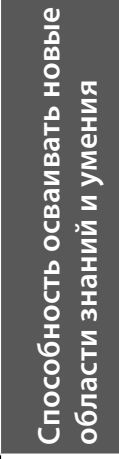 & 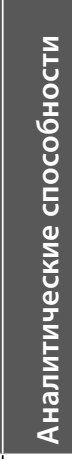 & 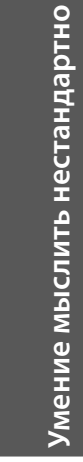 & 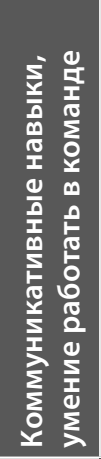 & 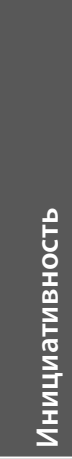 & 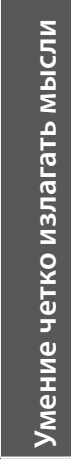 & 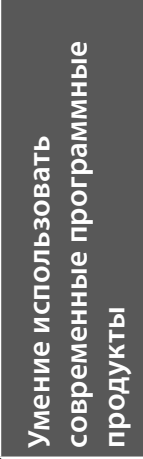 & 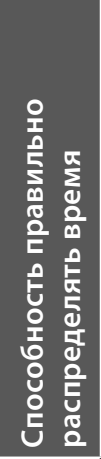 & 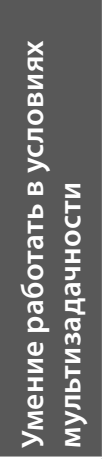 & 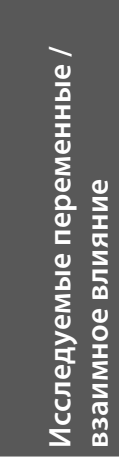 \\
\hline K1 & $\begin{array}{l}\text { Умение находить } \\
\text { и использовать } \\
\text { информацию } \\
\text { из различных источников }\end{array}$ & & $* * *$ & $* * *$ & $* * *$ & & & & $* * *$ & *** & $* * *$ & K1 \\
\hline K2 & $\begin{array}{l}\text { Способность осваивать } \\
\text { новые области знаний } \\
\text { и умения }\end{array}$ & *** & & $* * *$ & $* * *$ & *** & $* * *$ & & $* * *$ & $* * *$ & $* * *$ & K2 \\
\hline K3 & $\begin{array}{l}\text { Аналитические } \\
\text { способности }\end{array}$ & *** & $* * *$ & & & & & & $* * *$ & $* * *$ & $* * *$ & K3 \\
\hline K4 & $\begin{array}{l}\text { Умение мыслить } \\
\text { нестандартно }\end{array}$ & *** & & $* * *$ & & *** & $* * *$ & $* * *$ & & $* * *$ & $* * *$ & K4 \\
\hline K5 & $\begin{array}{l}\text { Коммуникативные } \\
\text { навыки, умение работать } \\
\text { в команде }\end{array}$ & *** & $* * *$ & $* * *$ & $* * *$ & & $* * *$ & $* * *$ & $* * *$ & $* * *$ & $* * *$ & K5 \\
\hline K6 & Инициативность & & $* * *$ & & $* * *$ & $* * *$ & & $* * *$ & & $* * *$ & $* * *$ & K6 \\
\hline K7 & $\begin{array}{l}\text { Умение четко излагать } \\
\text { мысли }\end{array}$ & & & $* * *$ & $* * *$ & $* * *$ & $* * *$ & & $* * *$ & & & K7 \\
\hline K8 & $\begin{array}{l}\text { Умение использовать } \\
\text { современные } \\
\text { программные продукты }\end{array}$ & *** & $* * *$ & $* * *$ & $* * *$ & *** & & $* * *$ & & & $* * *$ & K8 \\
\hline K9 & $\begin{array}{l}\text { Способность правильно } \\
\text { распределять время }\end{array}$ & *** & $* * *$ & & *** & *** & & & $* * *$ & & *** & K9 \\
\hline K10 & $\begin{array}{l}\text { Умение работать } \\
\text { в условиях } \\
\text { мультизадачности }\end{array}$ & *** & $* * *$ & $* * *$ & *** & $* * *$ & $* * *$ & & & $* * *$ & & K10 \\
\hline $\begin{array}{l}\text { Исс } \\
\text { взаv }\end{array}$ & $\begin{array}{l}\text { едуемые переменные / } \\
\text { иное влияние }\end{array}$ & K1 & K2 & K2 & K4 & K5 & K6 & K7 & K8 & K9 & K10 & \\
\hline
\end{tabular}


Таблица 3. Матрица взаимного влияния компетенций развития человеческого капитала в высокотехнологичных и наукоемких отраслях экономики

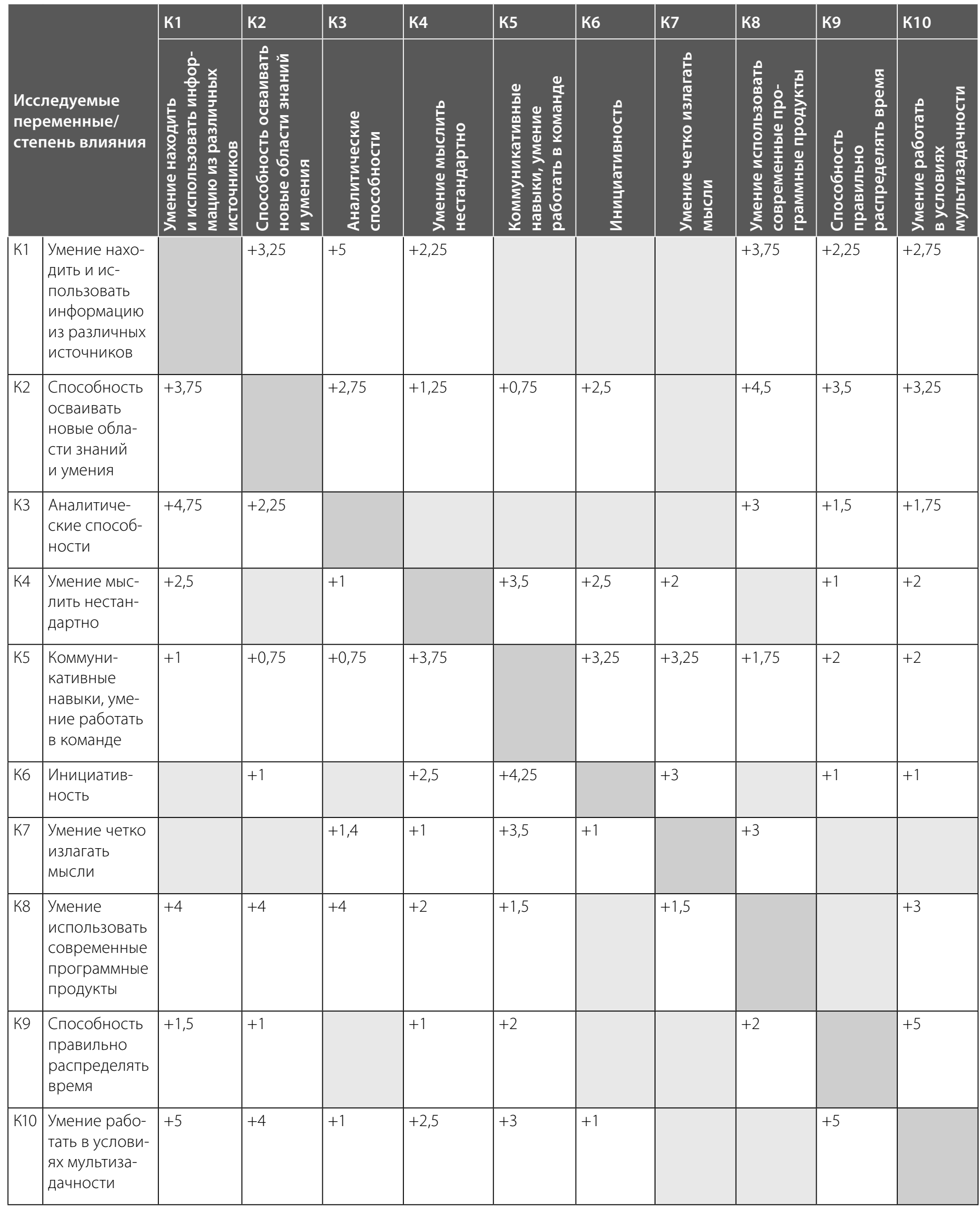

Источник: разработано автором 


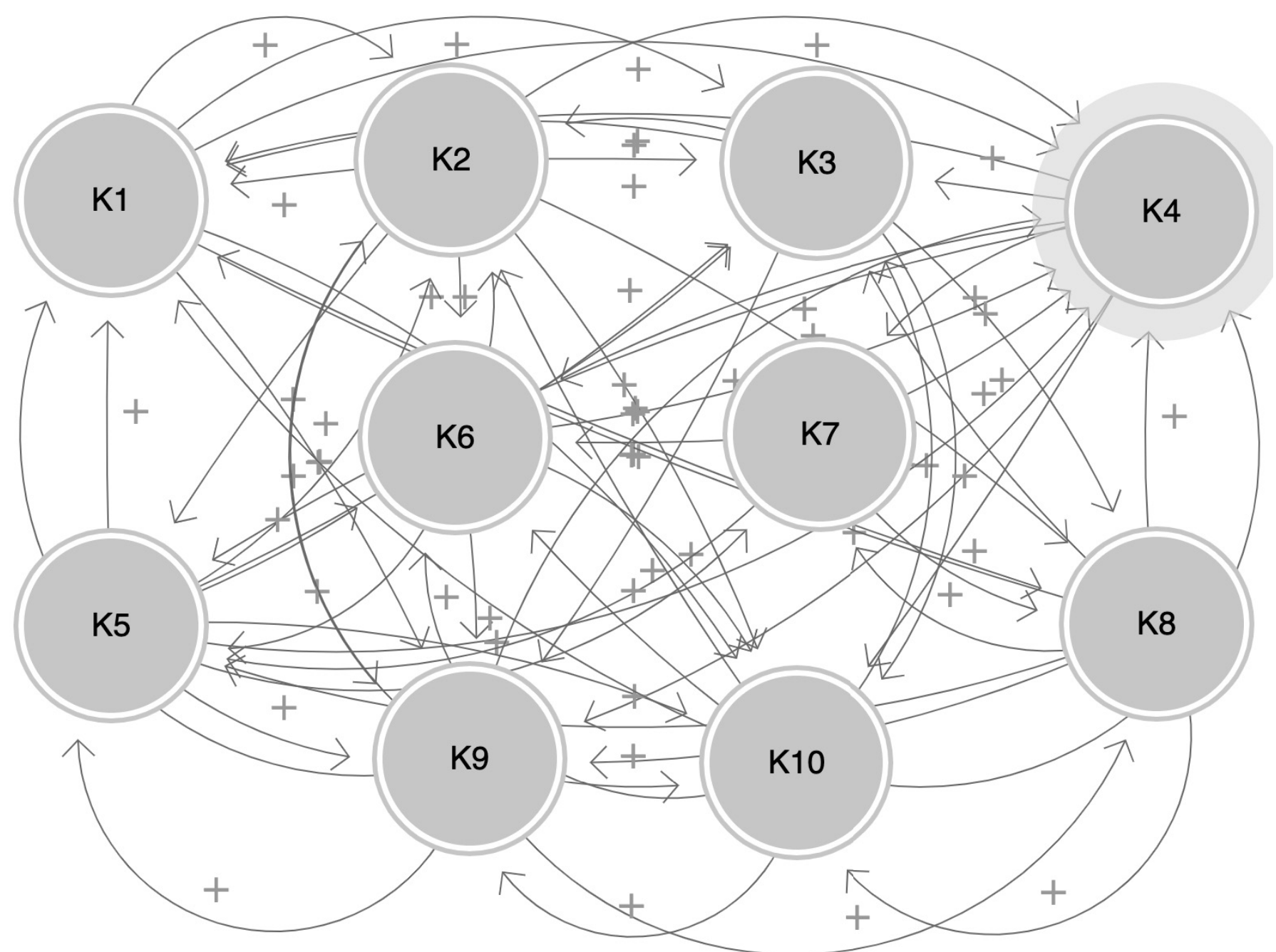

Рис. 1. Когнитивная карта компетенций развития человеческого капитала в высокотехнологичных и наукоемких отраслях экономики

Сценарии возможного взаимодействия анализируемых переменных могут изменяться в зависимости от особенностей объектов исследования, которыми в настоящей работе выступают компетенции развития человеческого капитала. Специфика данного объекта исследования определяется необходимостью изучения компетенций в применении к высокотехнологичным и наукоемким отраслям экономики.

Как известно, когнитивная карта выражается ориентированным графом $(X, W)$, где

$X=\left\{x_{i}\right\}$ - множество заданных факторов (применительно к данному исследованию - компетенций);

$W=\left\{w_{y}\right\}, w_{y} \in[-1 ;+1]-$ множество взаимосвязей, определяющих степень и направление взаимодействия между исследуемыми факторами (компетенциями человеческого капитала в высокотехнологичных и наукоемких отраслях экономики.
Степень взаимодействия межу переменными оценивается по шкале, представленной в таблице 1.

Когнитивная карта, описывающая нечеткое взаимное влияние компетенций развития человеческого капитала в высокотехнологичных и наукоемких отраслях экономики, была построена на анализе экспертных оценок; экспертами являлись представители административно-управленческого персонала вузов.

В целях анализа взаимного влияния были использованы десять наиболее значимых, по мнению автора, компетенций человеческого капитала высокотехнологичных и наукоемких отраслей экономики: умение находить и использовать информацию из различных источников; способность осваивать новые области знаний и умения; аналитические способности; умение мыслить нестандартно; коммуникативные навыки, умение работать в команде; инициативность; умение четко излагать мысли; умение использовать современные 

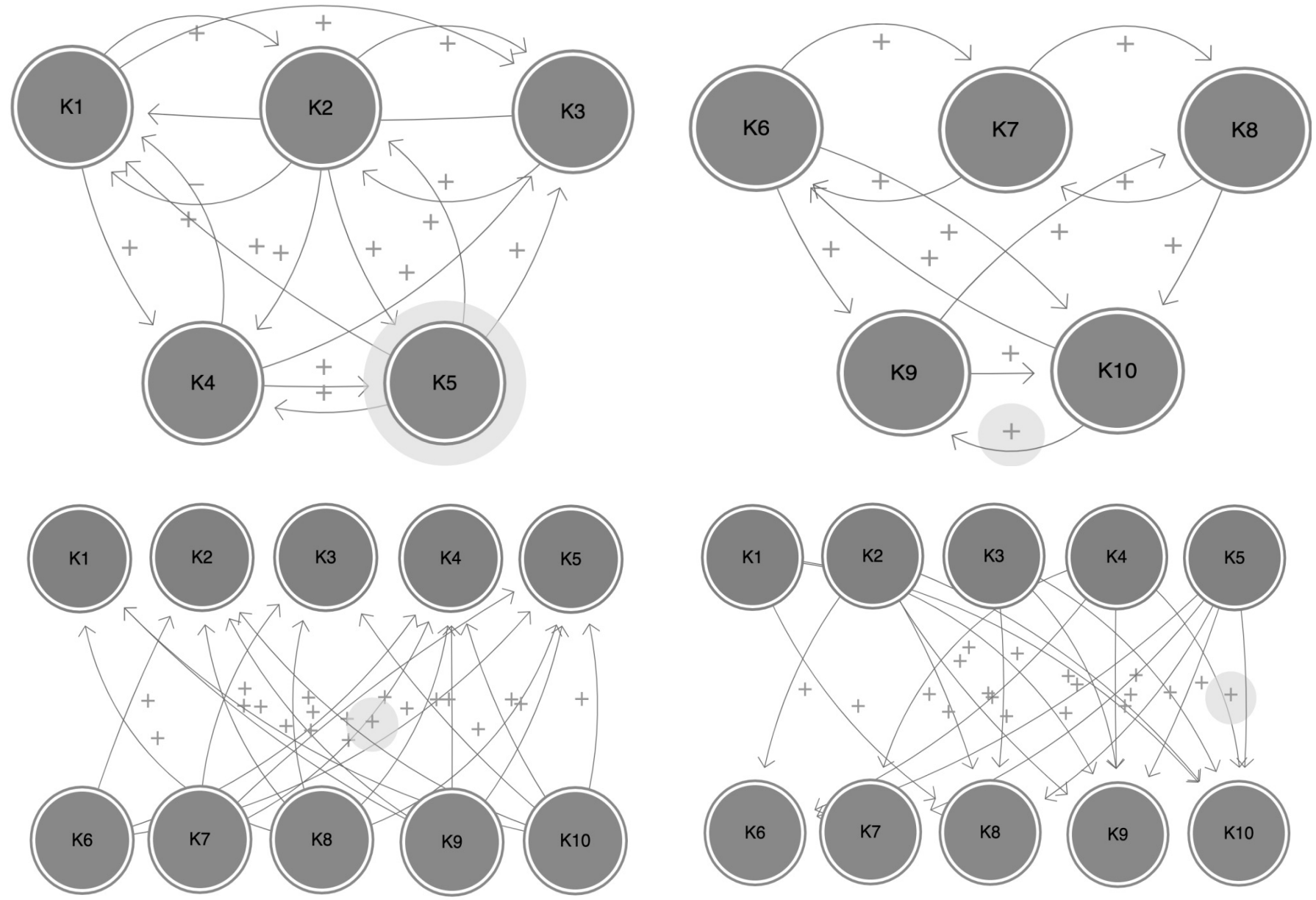

Рис. 2. Детализация когнитивной карты компетенций развития человеческого капитала в высокотехнологичных и наукоемких отраслях экономики

программные продукты; способность правильно распределять время; умение работать в условиях мультизадачности.

Для оценки взаимного влияния переменных была разработана анкета, представленная в форме карты и включающая выбор компетенций, между которыми отсутствуют взаимосвязи. Факты отсутствия влияния переменных друг на друга отмечались в анкете-карте как «0».

На основании экспертных оценок автору удалось составить матрицу взаимного влияния компетенций, представленную в таблице 2 и позволяющую исключить из выборки переменные, между которыми отсутствуют взаимосвязи. Исследованием установлено, что из 90 возможных вариаций взаимного влияния компетенций развития человеческого капитала в высокотехнологичных и наукоемких отраслях экономики в 24 комбинациях отсутствуют какие-либо взаимосвязи и их дальнейшая оценка нецелесообразна.
Следующим шагом в построении когнитивной карты была оценка интенсивности влияния друг на друга оставшихся переменных согласно предложенной в таблице 1 шкале. Результатом экспертной оценки стала разработка матрицы взаимного влияния исследуемых переменных - компетенций развития человеческого капитала в высокотехнологичных и наукоемких отраслях экономики,- учитывающая степень взаимного влияния факторов (таблица 3).

Матрица проиллюстрировала наиболее значимые взаимосвязи между переменными и позволила определить количество комбинаций взаимного влияния переменных, характеризующихся как «очень слабое положительное влияние», «слабое положительное влияние», «умеренное положительное влияние», «сильное положительное влияние» и «очень сильное положительное влияние»: очень слабое положительное влияние - 15; слабое положительное влияние - 15; умеренное положительное влияние - 15; сильное положительное влияние - 14; очень сильное положительное влияние - 7 . 
Таким образом, было установлено, что большинство комбинаций взаимного влияния переменных практически одинаково (15-15-15-14), исключение составляет только «сильное положительное влияние», которое наблюдается в 7 пересечениях исследуемых предикторов.

Представленная в таблице 3 матрица, построенная на основе анкетирования экспертов, послужила базой для построения нечёткой когнитивной карты развития человеческого капитала в высокотехнологичных и наукоемких отраслях экономики, в которой отражены взаимосвязи между переменными и степень их влияния друг на друга (рис. 1). Детализация когнитивной карты, позволяющая более детально проследить все установленные взаимосвязи, представлена на рис. 2.

Вершины карты представлены выбранными компетенциями (К1, К2, К3, K4, К5, К6, K7, К8, К9, К10), дуги с обозначенными знаками «+»- - указывают на направление взаимодействия между параметрами, интенсивность влияния проиллюстрирована в матрице (таблица 3).

Когнитивная карта позволяет определить структуру причинно-следственных связей между заданными компетенциями развития человеческого капитала в высокотехнологичных и наукоемких отраслях экономики и оценить последствия целенаправленного воздействия на установленные связи.

Так, при принятии мер относительно увеличения набора сотрудников, обладающих способностями осваивать новые области знаний и умения (K2) увеличится доля сотрудников, обладающих навыками использования современных программных продуктов (К10).

Примечательно, что построенная когнитивная карта не обладает отрицательными взаимосвязями, что свидетельствует о целесообразности воздействия на любую из компетенций, которая послужит генератором усиления тех переменных, с которыми она находится во взаимосвязи.

Таким образом, необходимо подчеркнуть, что при построении когнитивной карты важно учитывать достоверность полученных результатов, которая зависит от правильного выбора переменных и максимально точной оценки экспертов. Представленная когнитивная карта может быть усилена более сложными структурно-логическими взаимосвязями.

Если же говорить в целом, то когнитивная модель оценки компетенций человеческого капитала, востребованных в высокотехнологичных и наукоемких отраслях экономики, должна отвечать следующим требованиям: обеспечивать оценку человеческого капитала на индивидуальном уровне, микроуровне (человеческий капитал организации) и макроуровне (региональном или национальном уровне), учитывать самооценку сотрудника в соответствии с существующими моделями компетентности и учитывать мотивационный аспект сотрудника [15].

Статья подготовлена по результатам исследований, выполненных за счет бюджетных средств по государственному заданию Финуниверситету.

\section{ЛИТЕРАТУРА}

1. Axelrod R. The Structure of Decision: Cognitive Maps of Political Elites // Princeton. University Press. 1976.

2. Axelrod R. The Complexity of Cooperation: Agent-Based Models of Competition and Collaboration // Princeton. NJ: Princeton University Press. 1997.

3. Заграновская А.В. Системный анализ на основе нечетких когнитивных карт // Вестник Российского экономического университета имени Г.В. Плеханова. 2018. № 4 (100). С. 152-160

4. Ginis L.A. The use of fuzzy cognitive maps for the analysis of structure of social and economic system for the purpose of its sustainable development // Mediterranean Journal of social Sciences. 2015. T. 6. № 3. C. 113-118.

5. Аверкин А.Н., Ярушев С.А., Савинова В.М. Применение гибридных когнитивных систем поддержки принятия решений в рамках национального проекта “Цифровая экономика" // Мягкие измерения и вычисления. 2020. № 6 (31). С. 5-12.

6. Федулов А.С., Борисов В.В. Анализ нечетких реляционных когнитивных карт // Нейрокомпьютеры: разработка, применение. 2016. № 7. С. 7-14.

7. Ярушев С.А., Аверкин А.Н., Ефремова Н.А. Гибридные нечеткие когнитивные карты в задачах принятия решений и прогнозирования // Программные продукты, системы и алгоритмы. 2017. № 4. С. 18-25.

8. Борисов В.В., Федулов А.С. «Совместимые» нечеткие когнитивные карты // Системы компьютерной математики и их приложения. 2016. № 17. С. 41-43.

9. Evseev E., Kovalev I. Fuzzy cognitive map of research team activity // Lecture Notes in Computer Science. 2014. T. 8891. P. 342-350

10. Целых А.Н., Васильев В.С., Целых Л.А., Барковский С.А. Экспертная система на основе эффективных управлений с использованием когнитивных моделей // Известия ЮФу. Технические науки. 2017. № 3 (188). С. 78-96.

11. Васильев А.М., Черняховская Л.Р., Вульфин А.М. Моделирование процессов управления инновационной деятельностью в регионе в применением нечетких когнитивных карт // Вестник Астраханского государственного технического университета. Серия: Управление, вычислительная техника и информатика. 2020. № 3. С. 15-25. 
12. Евсеев Е.А. Нечеткая когнитивная модель деятельности научно-исследовательского коллектива // Вестник Санкт-Петербургского университета. Серия 12. Психология. Социология. Педагогика. 2015. № 2. С. 74-85.

13. Гинис Л.А., Гордиенко Л.В. Моделирование сложных систем: когнитивный теоретико-множественный подход. Южный федеральный университет, Инженерно-технологическая академия. Таганрог, 2016.

14. Tselykh A., Vasilev V., Tselykh L. Assessment of influence productivity in cognitive models // Artificial Intelligence Review. 2020. T. 53. № 7. P. 5383-5409.

15. Мельничук М.В. К вопросу об оценке компетенций человеческого капитала // Современная наука: актуальные проблемы теории и практики. Серия: Экономика и право. 2020. № 7. С. 56-60.

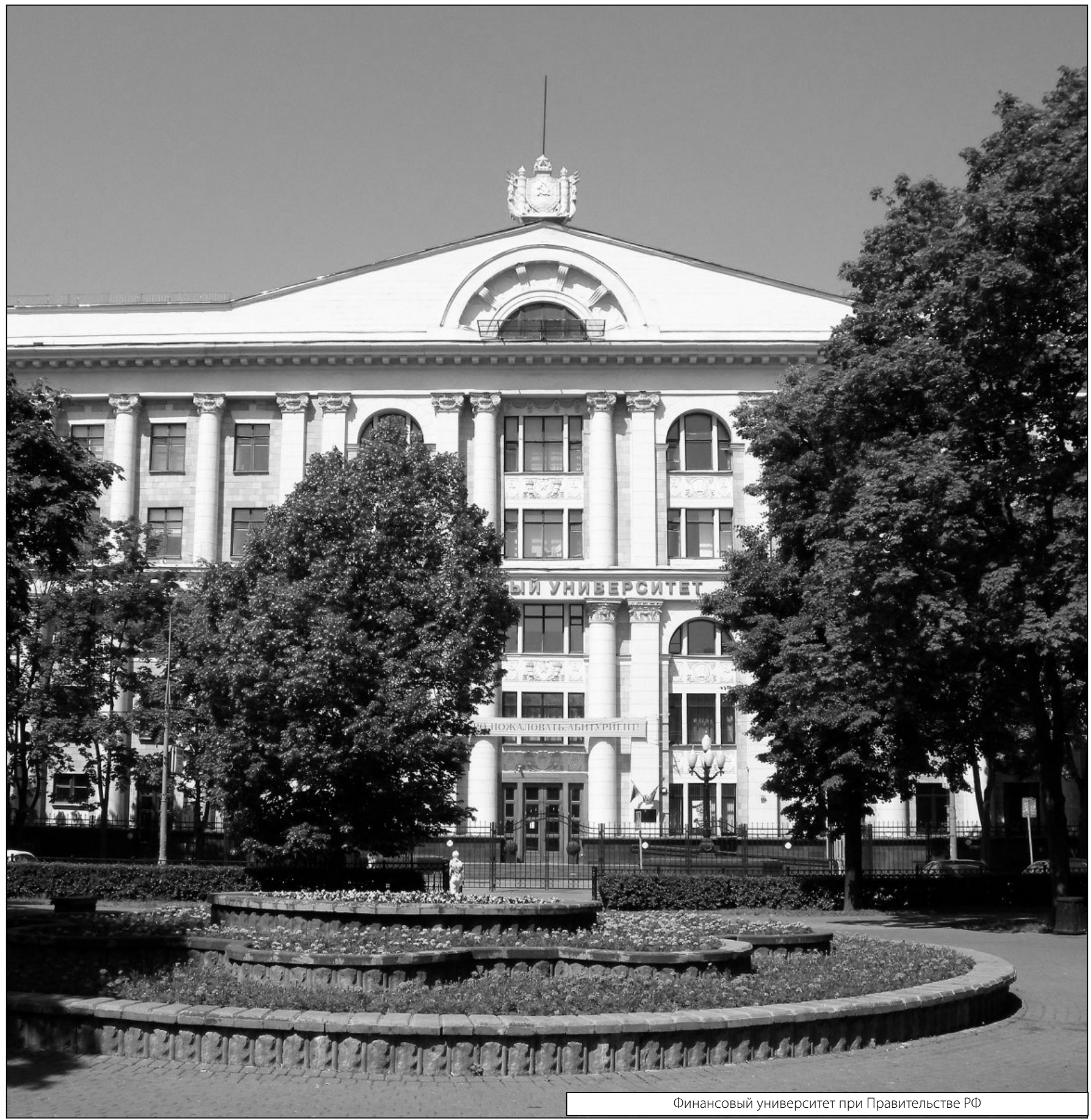

